\title{
Nursing audit conducted to gauge the documentation compliance by nursing professionals at Sagar hospital, Jayanagar within the domain of patient and family education rendered by nursing professionals during the course of their hospita
}

\author{
Mary Varghese ${ }^{1}$, Rekha S G ${ }^{2 *}$ \\ ${ }^{1}$ Senior Nurse Educator, ${ }^{2}$ Clinical Nurse Specialist, ${ }^{1}$ Dept. of Psychiatric Nursing, ${ }^{2}$ Dept. of OBG Nursing, ${ }^{1}$ Sagar \\ Hospital, Bengaluru, ${ }^{2}$ Lactation Consultant at Sagar Hospitals, Bengaluru, India \\ *Corresponding Author: Rekha S G \\ Email: 73rekha@gmail.com
}

\begin{abstract}
Nursing documentation is that the record of medical care that's planned and delivered to individual clients by qualified nurses or other caregivers under the direction of a professional nurse. It contains information in accordance with the steps of the nursing process. It constitutes an integral a part of the nurse's daily work. Meticulous nursing documentation is a crucial a part of patient care. The delivery of excellent care and therefore the ability to speak effectively about patient care depends on the standard of data available to all or any health care professionals. One important a part of this information is nursing documentation in medical care plans.

Aim of the Study: to gauge the effectiveness of documentation of Patient education process using Nursing audit at Sagar Hospital, Bangalore.

Materials and Methods: The case records were chosen by simple systematic sampling method and every file was analysed employing a structured check list. the whole data were combined into one result for the whole excel sheet. Concurrent patient education form review within the case record were analysed employing a Structured checklist during 1st Nov 2018 to 31st OCT 2019 (12months). Care file were selected employing a simple Systemic Sampling Technique and about 50\% of admissions were included within the study and 4317(53.38\%) of the entire admission.

Results: Totally compliant were 3726 (86.30\%), partially compliant were 399 (9.24\%) and non-compliant were 192 (4.44\%). the very best compliance of documentation was seen in safe parenting practices, immunization and disease specific information (99.30\%). the smallest amount compliance was seen in pain management and documentation 443 (partially and non-compliant category constitutes $11.07 \%$. Data also revealed compliance with disease specific information $99 \%$, medication management $99 \%$, hand hygiene was $91 \%$, pain assessment $81 \%$, fall prevention $62 \%$, pressure ulcer prevention $12 \%$, Immunization $9 \%$.

Conclusion: Use a standardised form will help to make sure consistency and improve the standard of the written account. There should be a scientific approach to providing medical care (the nursing process) and this could be documented consistently. The nursing record should include assessment, planning, implementation, and evaluation of care.
\end{abstract}

Keywords: Nursing audit, Documentation, Patient education process, Nursing process, Compliances.

\section{Introduction}

Patient education is that the procedure during which individuals with health occupations impart information to patients about their own health status and wishes. It aims to enable patients to enhance their own health by changing their health-related behaviours. Education are often therapeutic or used for disease prevention. This process is neither just information-sharing nor websites are a panacea. Nurse plays key role in imparting change in behaviour patterns for better care outcomes.

Nursing documentation constitutes an integral a part of the nurse's daily work. ${ }^{1}$ Meticulous nursing documentation is a crucial a part of patient care.

Importance of Nursing Documentation are - they constitute an integral a part of the nurse's daily work. ${ }^{2}$ Meticulous nursing documentation is a crucial a part of multi-professional patient care. The delivery of excellent care and therefore the ability to speak effectively about patient care depends on the standard of data available to all or any health care professionals. One important a part of this information is nursing documentation in medical care plans. ${ }^{3}$

A nursing audit is that the process of evaluating the standard of medical care through the review of clinical records made by healthcare professionals. It helps healthcare institutions make sure that patients consistently receive quality patient care and allows nurse managers to work out healthcare improvement opportunities. Nursing documentation is crucial to top quality, good and safe medical care. 


\section{Background of the study}

The nursing process has been used as a foundation for medical care and nursing documentation. The nursing process involves assessing, planning, implementing and evaluating patient situations, with the last word goal of preventing or resolving problematic situations. ${ }^{4}$ American Nurses Association defines nursing process six steps: assessment, diagnosis, outcomes, identifications, planning, implementation and evaluation. ${ }^{5}$ Earlier studies have reported that nursing documentation has conformed to the nursing process, and therefore the use of the nursing process has been shown to enhance legislative compliance and completeness of nursing documentation. ${ }^{7}$ At an equivalent time, studies have also reported deficiencies in nursing documentation consistent with the nursing process. $^{8-11}$

\section{Need for the Audit}

The health needs of the society are growing as we sleep in a complicated technological world. it's our responsibility to supply client centered, cost effective $\&$ evidence-based care to all or any the clients. Successful patient education can improve health outcomes, reduce hospital readmission \& improve patient \& family satisfaction. Providing patient \& family education is a crucial nursing role \& core competency of nursing practice. The documentation enhances adherence to protocols and effectiveness are often easily elicited, as this is often one among the wants of accreditation process.

\section{Title of the study}

Nursing audit conducted to gauge the documentation compliance by Nursing professionals at Sagar Hospital, Jayanagar within the domain of patient and family education rendered by Nursing professionals during the course of their hospital stay.

\section{Objectives of the study}

1. To evaluate the effectiveness of documentation of Patient education process finished in patient at Sagar Hospital

2. To improve the patient safety and quality of care in sight of International Patient Safety Goals
3. To identify the deficiency of data and compliance to teaching in order that, medical care plan is often planned and modified.

Methods utilized in this audit are;

Audit Design: concurrent patient education form review within the case record

Audit Tool: A Structured checklist

TIME FRAME: 1st Nov 2018 TO 31st OCT 2019 (12months)

SAMPLING TECHNIQUE: Simple Systemic Sampling Technique

Sample Size: $50 \%$ of admissions chosen from each month (4317)

Population Size: 8086 number of admissions during the study period

The patient Health Education dealt - Hygiene, pain assessment, fall prevention, pressure ulcer prevention, immunization, disease specific information, medication management, safe parenting practices.

\section{Research Process}

An audit instrument was developed within the national development project for electronic nursing documentation. Permission was obtained from the concerned authority to conduct the audit. The audit was conducted altogether nursing units which had been using the standardised nursing documentation for a minimum of two years. Patients' personal details were faraway from the case files before it had been sent to the auditors. On a mean 674 patients were admitted to the hospital monthly with the entire number of 8086 total admissions in year the 2018-19. The sample representation is 439 from paediatric category, which constitutes, $10.03 \%$ of the entire population. The case records were chosen by simple systematic sampling method and every file was analysed employing a structured check list. the whole data were combined into one result for the whole excel sheet. The nursing documentation audit was conducted by two auditors, which was considered to extend its reliability. Further, a scientific survey instrument was developed to collect data on nurses, experiences of the documentation.

Table 1: Showing month wise compliance rate of Patient Education

\begin{tabular}{|c|c|c|c|c|c|c|c|c|c|c|c|c|c|c|}
\hline & $\begin{array}{c}\text { Nov } \\
18\end{array}$ & $\begin{array}{c}\text { Dec } \\
18\end{array}$ & $\begin{array}{c}\text { Jan } \\
19\end{array}$ & $\begin{array}{c}\text { Feb } \\
19\end{array}$ & $\begin{array}{c}\text { Mar } \\
19\end{array}$ & $\begin{array}{c}\text { Apr } \\
19\end{array}$ & $\begin{array}{c}\text { May } \\
19\end{array}$ & $\begin{array}{c}\text { Jun } \\
19\end{array}$ & $\begin{array}{c}\text { Jul } \\
19 \\
\end{array}$ & $\begin{array}{c}\text { Aug } \\
19\end{array}$ & $\begin{array}{c}\text { Sep } \\
19\end{array}$ & $\begin{array}{c}\text { Oct } \\
19 \\
\end{array}$ & Total & $\%$ \\
\hline IP No. & 614 & 583 & 586 & 559 & 606 & 647 & 632 & 743 & 916 & 817 & 737 & 646 & 8086 & \\
\hline Chart Assessed & 350 & 330 & 332 & 200 & 250 & 315 & 325 & 450 & 500 & 550 & 380 & 335 & 4317 & 53.38 \\
\hline Total Compliant & 229 & 220 & 200 & 175 & 185 & 225 & 230 & 235 & 210 & 375 & 345 & 226 & 3726 & 86.30 \\
\hline Partial compliant & 64 & 31 & 38 & 40 & 15 & 10 & 13 & 20 & 22 & 15 & 15 & 16 & 399 & 09.24 \\
\hline Not compliant & 08 & 10 & 09 & 08 & 12 & 14 & 15 & 14 & 16 & 12 & 15 & 11 & 192 & 04.44 \\
\hline
\end{tabular}




\section{Analysis}

The audit process included analysing approximately 360 charts per month which constitutes $4317(53.38 \%)$ the sample size. Though the general compliance rate remained constant during the audit period around $87.10 \%$ and total feedback forms assessed were $4317(53.38 \%)$ of the entire admission. Totally compliant were 3726 (86.30\%), partially compliant were $399(9.24 \%)$ and non-compliant were 192 $(4.44 \%)$.

The highest compliance of documentation was seen in safe parenting practices, immunization and disease specific information $(99.30 \%)$. the smallest amount compliance was seen in pain management and documentation 443 (partially and non-compliant category (443) constitutes $11.07 \%$. (The pain assessment to be assessed by Doctors and Nurses; any mismatch of the assessment, interpretation, titration of pain management, outcome gaps were captured as non-compliance, since Pain is taken into account as 5 th vital sign).

Data also revealed compliance with disease specific information $99 \%$, medication management $99 \%$, hand hygiene was $91 \%$, pain assessment $81 \%$, fall prevention $62 \%$, pressure ulcer prevention $12 \%$, Immunization $9 \%$.

\section{Recommendation}

1. Make sure that proper admission policy and Initial Assessment is followed

2. Create an awareness among the staff associated with patient education by regular auditing.

3. More emphasis to tend to patient education specially related to: Hand Hygiene, Pain assessment, Pressure Injury prevention.

4. Continuous guiding and supporting the new staff through proper mentor ship.

5. Effective supervision by the Nursing Leadership using audit exercise as a motivational tool.

6. This audit is an ongoing process as a requirement for NABH and Nursing Excellence Certification requirement.

\section{Conclusion}

The Nursing audit taught us to specialise in to start educating patients with every encounter from admission. determine what the patient already knows. Correct any misinformation. Feed patient's information in layman's terms. Utilize visual aids as often as possible. Use return demonstration when administering care. Involve the patient from the very first treatment (Wound care, Insulin injections, back care etc.). Provide patients with information about signs and symptoms of their condition which will require immediate attention; whom and when to approach the hospital for further management.

\section{Source of funding}

None.

\section{Conflict of interest}

None.

\section{References}

1. Heartfield M. Nursing documentation and nursing practice: a discourse analysis. $J$ Adv Nurs 1996;24:98-103. [PubMed] [Google Scholar]

2. Urquhart C, Currell R, Grant MJ, Hardiger NR. Nursing record systems: effects on nursing practise and healthcare outcomes. Cochrane Database Syat. Rev 2009;(1) doi: 10.1002/14651858. art. no.; cd002099.pub2. [CrossRef] [Google Scholar]

3. Yura $\mathrm{H}$, Walsh $\mathrm{M}$. The nursing process: assessing, planning, implementing, evaluating. third ed. appletoncentury-crofts; New York: 1978. [Google Scholar]

4. Saba VK, McCormick KA. Essentials of Nursing Informatics. Fifth edition. The McGraw-Hill Companies; 2011. [Google Scholar]

5. Ehrenberg A, Birgersson C. Nursing documentation of leg ulcers: Adherence to clinical guidelines during a Swedish primary health care district. Scand $J$ Caring Sci 2003;17:278-84. [PubMed] [Google Scholar]

6. Ammenwerth E, Eichstadter R, Haux R, Pohl U, Rebel S, Ziegler S. A randomized evaluation of a computer-based nursing documentation system. Method Inf Med 2001;40:61-8. [PubMed] [Google Scholar]

7. Mahler C, Ammenwerth E, Wagner A, Tautz A, Happek T, Hoppe B et al. Effects of a computer-based nursing documentation system on the standard of nursing documentation. J Med Syst 2007;31:274-82. [PubMed] [Google Scholar]

8. Björvell C, Wredling R, Thorell-Ekstrand I. Long-term increase in quality of nursing documentation: effects of a comprehensive intervention. Scan $J$ Caring Sci 2002;16:34-42. [PubMed] [Google Scholar]

9. Törnvall E, Wilhelmsson S, Wahren LK. Electronic nursing documentation in primary health care. Scan J Caring sci 2004;18:310-317. [PubMed] [Google Scholar]

10. Törnvall E, Wahren LK, Wilhelmsson S. Impact of medical care management on nursing documentation. J Nurs Manag 2007;15:634-642. [PubMed] [Google Scholar]

11. Averill CB, Marek KD, Zielstorff R, Kneeddler J, Delaney C, Milholland DK et al. ANA standards for nursing data sets in information systems. Comput Nurs 1998;16:157-61. [PubMed] [Google Scholar]

12. Saranto K, Kinnunen U-M. Evaluating nursing documentation - research designs and methods: systematic review. Journal of advanced nursing. 65(3):464-476. [PubMed] [Google Scholar]

13. Waneka R, Spetz J. Hospital information technology systems, impact on nurses and medical care. J Nurs Administration 40(12):509-15. [PubMed] [Google Scholar] 
14. Häyrinen K, Saranto K, Nykänen P. Definition, structure, content, use and impacts of electronic health records. Int $J$ $M$ Inf 2008;79:291-304. [PubMed] [Google Scholar]
How to cite: Varghese M, Rekha SG, Nursing audit conducted to gauge the documentation compliance by nursing professionals at Sagar hospital, Jayanagar within the domain of patient and family education rendered by Nursing professionals during the course of their hospital. IP J Paediatr Nurs Sci 2020;3(1):15-8. 